\title{
FRACTURE RESISTANCE OF COMPOSITE STRUCTURS FROM HEMP BIO-FIBERS
}

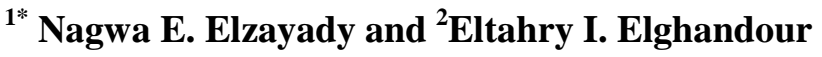 \\ ${ }^{1 *}$ Department of Mechanical and Aerospace Engineering, Institute of Aviation Engineering and Technology, \\ Egypt \\ ${ }^{2}$ Department of Mechanical Engineering, California Polytechnic State University-San Luis Obispo, \\ San Luis Obispo, USA \\ *Corresponding Author E-mail: goga.2008@yahoo.com
}

\begin{abstract}
Lightweight sandwich structures are used in the aircraft industry because of their high strength-to-weight and stiffness-to-weight ratios. Structural components are often subjected to edge loads in compression or tension. The sandwich structure under the edge compression load exhibits excellent compression capacity. On the contrary of loading under flatwise compression, the sandwich under edge compression undergoes drastic tearing and fracture. The current study is based on experimental work on sandwich-structures made of carbon fiber and natural fiber reinforced face sheets with different core materials. The natural fiber (hemp) is highlighted in the current study to improve the fracture resistance of skins. The hemp-skin demonstrates comparable compression properties to those of carbon fiber under edge compressive load. The skin from hemp has great fracture resistance while the carbon one experienced dramatic fracture, tearing, and delamination. This outcome of the current study, in addition to the lightweight, lowcost ease handling, simple manufacturing, and eco-friendship make the hemp a competitive industrial material in aerospace applications. More details about the manufacturing and the failure modes are discussed as well.
\end{abstract}

Keywords: Fracture Resistance, Natural fiber, Composite Materials, Sandwich Structure

\section{INTRODUCTION}

Improvement of mechanical properties of structures is a big demand in aerospace applications as they are highly efficient when it comes to light-weight and stiff components [1-5]. The sandwich structure plays an essential role in such modern manufacturing industries [6-8]. The properties of composite materials are affected very much by the structure components [9-11]. Reinforced plastics composite such as fiberglass, carbon fiber, and Kevlar, Foam and honeycomb are the components used widely in the

Received:19October, 2020, Accepted:24October, 2020 manufacturing of sandwich structure [9 \&12]. The carbon fiber reinforced plastic (CFRP) composite is considered as one of the lightest components but it is a relatively high-cost material in the manufacturing process [13]. Also, natural composite materials from plants are; wood, hemp, and bamboo [9, $10 \& 14]$ are used as cores or skin facings in sandwich members. Also, core is made out of cellular materials (foam, honeycomb) [15]. Some honeycomb structures are natural, they include; honeycomb weathering in rocks, beehives and tripe [16]. Due to the growth of environmental awareness, the change to the 
eco-friendly materials at affordable costs is highlighted [2, 14 \& 17-22]. Research on this recent type of structural material is very beneficial for promoting the application of green and light-weight functional materials [23]. Utilization of the natural textile in the composite as fiber reinforcement is well recommended for high-performance. These fibers as their advantages on good fiber orientation, fiber distribution, high strength, and easy to handle during composite fabrication are preferred [14]. Among the natural fibers is the hemp. Hemp is a socalled bast fiber, the hemp plant (Cannabis Sativa) is used for making this fiber. It is utilized for textile production. Hemp was a common natural fiber before cotton became a mass product. Today the market is dominated by Chinese hemp because of its strength also in bio-composites. The ecological advantages of hemp are; no irrigation needed, no chemical treatment, and $100 \%$ biodegradable. Hemp is nowadays recognized as a sustainable fiber [24]. However, in the sandwich structure, various failure modes are affected by the material properties of the components (facings, adhesive, and core), geometric, design, and type of loading [25]. Loading direction affects the failure mode strongly whereas the sandwich fractures under flatwise compression differ from edgewise compressions'. Edgewise compressions testing has been studied early on metallic skin facing-sandwich ( $\mathrm{Ti}$ and $\mathrm{Al}$ ) by Paul $\mathrm{M}$. Jenkinson [26] in 1966 for aerospace purposes. He adopted the edge compression in his study because the flight structural components are often subjected to edge loads in tension or compression. Compared to metal, fracture mechanisms of composite materials are still in the development process [27]. Generally, woven fiber reinforced plastic composite laminates carry loads in many directions [28] and frequently undergo interlaminar fracture [29].
Interlaminar shear fracture and delamination of the laminate results in stiffness and strength reduction [30] Edgewise compressive loading of sandwich constructions stresses the facings and the core-to-facing bonds as well. In sandwich members under edgewise compression, compressive failure of the skins occurs if the core is sufficiently stiff. Otherwise, facing wrinkling takes place first and the core is still in the linear elastic range [25]. Also due to the thin thickness of the face sheets, they always experience face buckling and local failure modes. Fiber rupture at upper and lower skin edges, core shear fractures, delamination, and face/core debonding are common failures in sandwich structure [31]. The factors that affect the failure modes highly are the strain rate, load direction, and the material types of sandwich components. Low-velocity impact properties of composite fiber metallic laminates and quasi-static indentation have been studied before by Nagwa Elzayady et. al [30]. They proved good properties in both quasi-static and low-velocity strain rates in a laminate composite. Static loading is highlighted in the current research. The current work aims to improve the properties of light-weight composite sandwich structure based on utilizing the eco-friend materials. Balsa wood, foam, and paper board (carton) honeycomb are selected as core materials and two different skins; one is from woven carbon fiber composite and another is a biocomposite from the hemp fabric. The study focused on enhancing the fracture resistance of sandwich structure under edgecompression which is a big shortage when using composite carbon fiber skin in heavy applications of aircraft.

\section{EXPERIMENTAL WORK}

\subsection{Fabrication Method}

Sandwich-structures are made of skin sheets from carbon fiber and natural (hemp) fiber 
reinforced with epoxy while the core is made from different materials. The raw materials are displayed in Figure 1 are used in the fabrication processes. The manufacturing has been made in three consequent steps; 1 Preparation the first skin from carbon fiber by cutting $0.25 \mathrm{~mm}$ - thickness woven prepreg carbon fiber ply into rectangular plies with large sizes, laying up the plies without adding epoxy resin to be ready for the curing process. 2- Preparing the second skin from hemp textile; the hemp also was prepared by the hand laying-up with adding epoxy (Figure 2) and then cured as the same as carbon in the autoclave. 3- Different core sheets were held between every two similar skins before curing. The cores are balsa wood, foam, and paper board (carton) honeycomb. The curing process was carried out using a vacuum bag technique for 2 hours at $130{ }^{\circ} \mathrm{C}$. The details of the curing system of the carbon composite were discussed before by Nagwa Elzayady \& Eltahry Elghandour [1]. The cooked specimens (Figure 3) were cut using a diamond saw into groups according to the skin and core types (Figure 4). All wood core members are having dimensions $=(85 \times$ $38 \times 14) \mathrm{mm}$ which are designated by length1 samples while the dimensions of the specimens having foam-core and honeycomb-core $=(126 \times 38 \times 14)$ are designated by length- 2 samples. The configurations of the samples are listed in Table 1 as an average of three values. For the difficulty of obtaining the same sizes in all conditions, the comparison is based on the specific properties (properties-to-weight ratio). Also, in the manufacturing processes, the similar weight of the final products having different skin sheets has been considered as much as was possible to facilitate the comparison.
Table 1 Configurations of the samples

\begin{tabular}{|l|l|l|l|l|l|l|}
\hline Mat. & $\begin{array}{l}\text { H- } \\
\text { W } \\
\text { W }\end{array}$ & $\begin{array}{l}\text { C- } \\
\text { H-F }\end{array}$ & C-F & $\begin{array}{l}\text { H- } \\
\text { Cart } \\
\cdot\end{array}$ & $\begin{array}{l}\text { C- } \\
\text { Cart } \\
\cdot\end{array}$ \\
\hline $\begin{array}{l}\text { V } \\
\left(\mathrm{cm}^{3}\right)\end{array}$ & 45.2 & 45.2 & 67.03 & 67.03 & 67.03 & 67.03 \\
\hline $\begin{array}{l}\text { M } \\
(\mathrm{gm})\end{array}$ & 12 & 12 & 13 & 11 & 12 & 10 \\
\hline $\begin{array}{l}\square(\mathrm{k} \\
\left.\mathrm{g} / \mathrm{m}^{3}\right)\end{array}$ & 265 & 260 & 190 & 164 & 179 & 149 \\
\hline
\end{tabular}

$\mathrm{H}$; is Hemp, C; is Carbon, W; is Wood, Cart.; is Carton

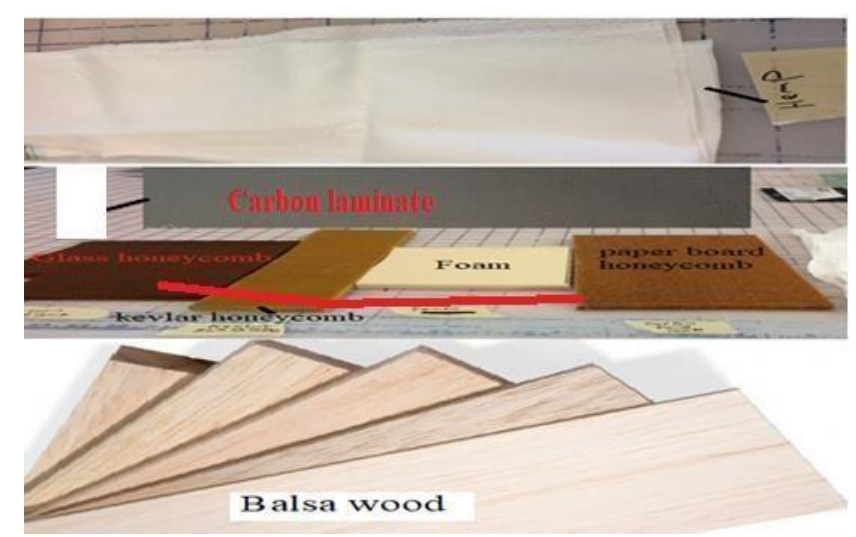

Fig.1 Raw materials of cores and skins

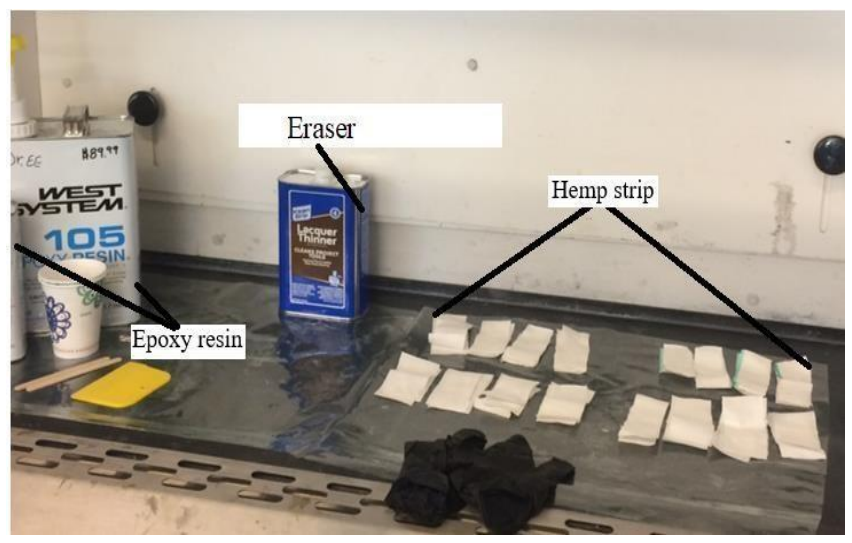

Fig. 2 Preparation of the hemp composite by hand layingup method 


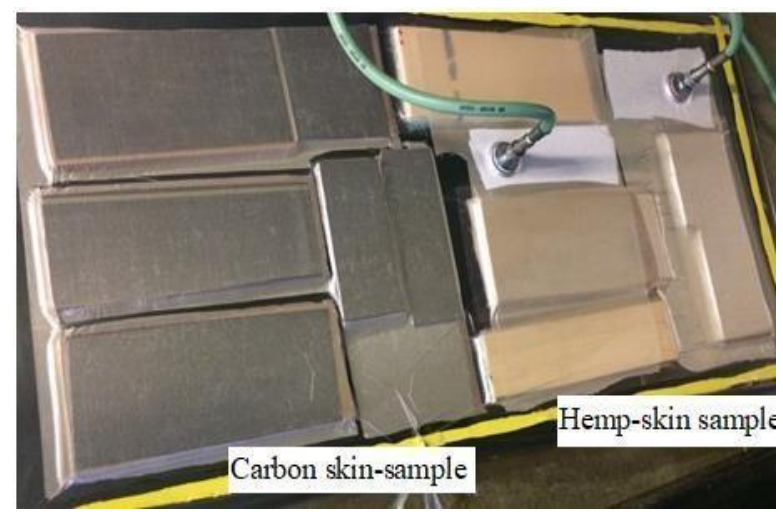

Fig. 3 Samples after the curing process in the autoclave

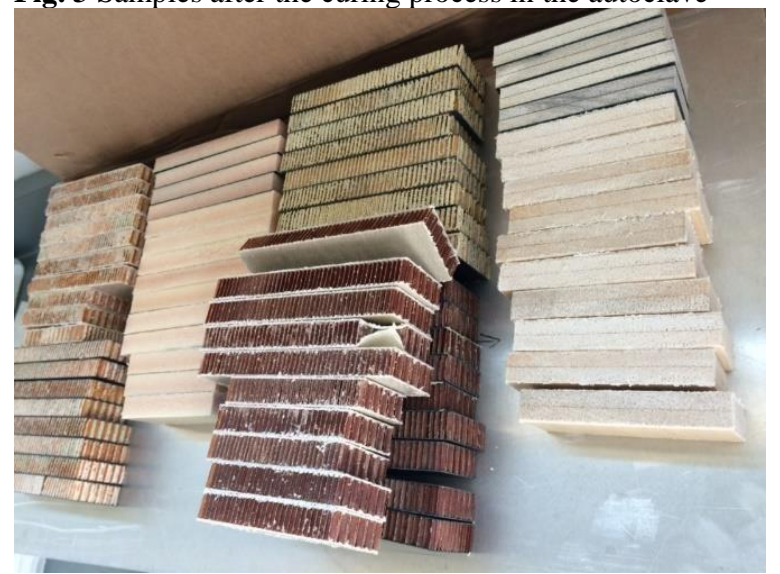

Fig. 4 Finished specimens

\subsection{Testing}

Three samples were prepared from each configuration to confirm the results. Testing has been carried out onto 20000 lbs Instron universal testing machine. The samples were located freely on the lower head of the machine and the load was applied parallel to the skin sheet (Figure 5). Examining their compression resistance was under the edgewise compression test. The output data were on the machine attached computer.

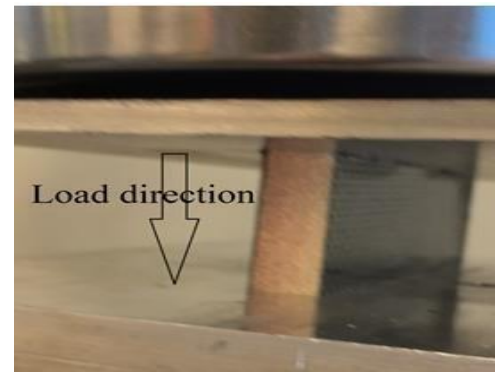

Fig. 5 Load direction in edge compression onto an example of the tested sample

\section{RESULTS AND DISCUSSION}

The results of the compression test are plotted in Excel sheets, the comparison at results is based on the skin type and the three conditions are discussed according to three different materials of the core. Each condition discusses two graphs, one for the behavior of the force-displacement curve and the other for the values of properties and the specific properties to weight ratio. The graphs of the three conditions are in Figures; $6-11$. The analysis is oriented to the specific properties to deliver appropriate comparison and avoid miss leading. In other words, comparing the higher property to another counterpart, it may be on the expense of the weight, so the structure properties relative to its overall weight is helpful. Composites differ from isotropic materials as considerable control can be oriented to the larger-scale structure. On the contrary to the metallic behavior under a compression load, the force-displacement curve of under edge compression fluctuates. This is plain from the force-displacement charts in Figure; 6, 8 $\&$ 10. The phenomenon attributes to the nature of the orthotropic structure of the sandwich with its different component materials. These different materials of the sandwich make the structure deforms in a combined way; elastic and plastic during loading. This makes the tested member compressed at certain displacements and expands at others. This phenomenon does not exist significantly in the flat compression testing of the sandwich. The three conditions of different cores are discussed in the following paragraphs.

\subsection{Wood-core}

The force-displacement curves of the compression test of wood-core specimens are plotted in Figure 6, Both curves of hemp and carbon-skin sandwich are so far similar to the Maximum force value, while the carbon-skin one absorbs more energy in the 
plastic stage. The more absorbed energy is due to the long distance that member displaced $(10 \mathrm{~mm})$ as in Figure 6. This observation exhibits the importance of the plastic stage like the elastic one in the sandwich structure under loading. The hemp-skin carries as much as the compression force of the carbon-fiber one.

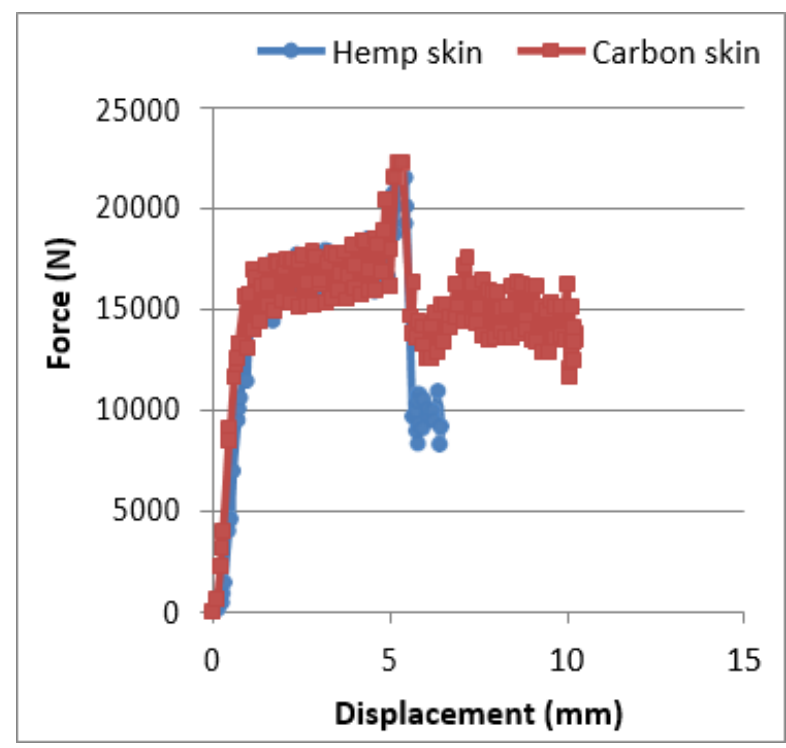

Fig. 6 Force- displacement of wood-core samples having length-1 (85mm)

The properties of both kinds of sandwich structures are graphed in Figure 7. The maximum force values are $22.2 \mathrm{kN}$ and 21 $\mathrm{kN}$ for carbon samples and hemp samples respectively. Also other properties; stiffness, specific force, and specific stiffness rest of properties, comparable values for both skins when the wood core is inserted in between. On the other hand, the specific properties of both kinds have approximate value $=1.8$ $\mathrm{kN} / \mathrm{gm}$ which is extremely high as a specific crushing force could be carried by a sandwich member. The specific stiffness also is high numbers; approximately, 1.5 $(\mathrm{KN} / \mathrm{mm}) / \mathrm{gm}$ for both skins. The high values of the stiffness in hemp samples probably refer to using the balsa wood as a stiff core material. Also testing under the edge compression and as a result taking the advantage of the second moment of area raises the stiffness values. Thus, the hemp- skin with wood core carries a compression load as much as the carbon fiber.

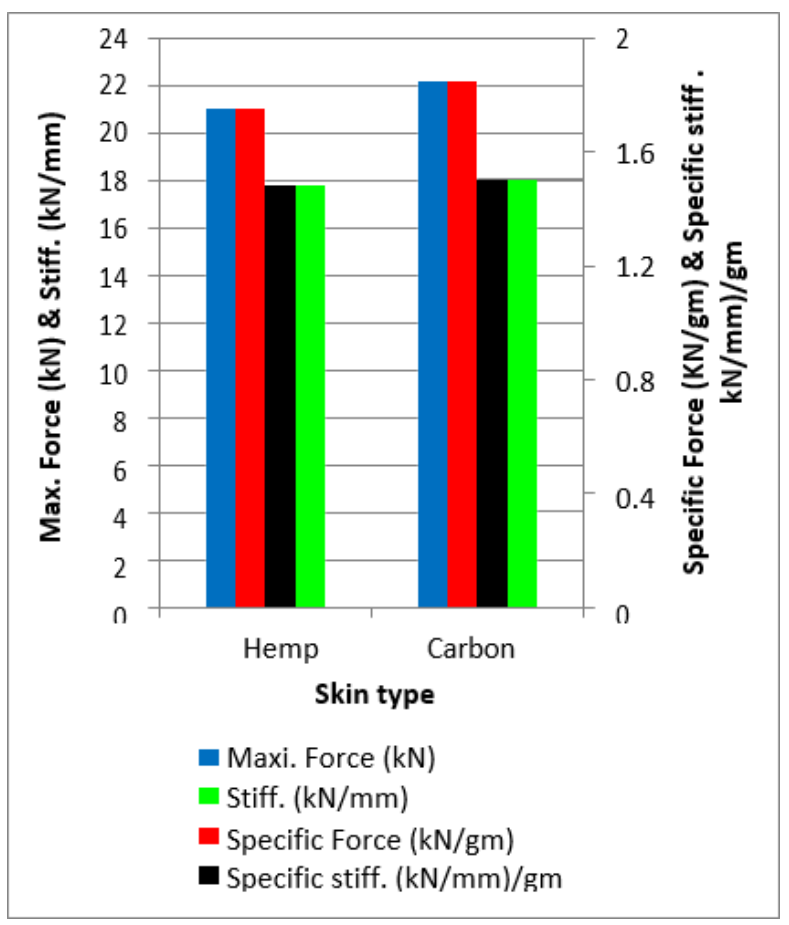

Fig. 7 Properties and specific properties of wood-core samples having length-1 (85mm)

\subsection{Foam-core}

The results of the foam-core sandwich members are plotted in Figure 8 and Figure 9 for the force-displacement curves and the properties respectively. The behaviors of samples of both kinds of skin with foam core are somehow similar to each other. The behavior is different from that in the wood core case. This is a reasonable output as the foam is less-strength material than the balsa wood. Hence, the members having foam cores are unable to carry high force magnitude or displace long distance. Despite the size of these samples is one-third that of wood cores'. For that, the graph in Figure 9 is plotted to obtain the specific properties of the sandwich structure in the case of using foam cores. Therefore; the results could be 
compared in both cases; wood-core and foam-core form (Figure $7 \&$ Figure 9).

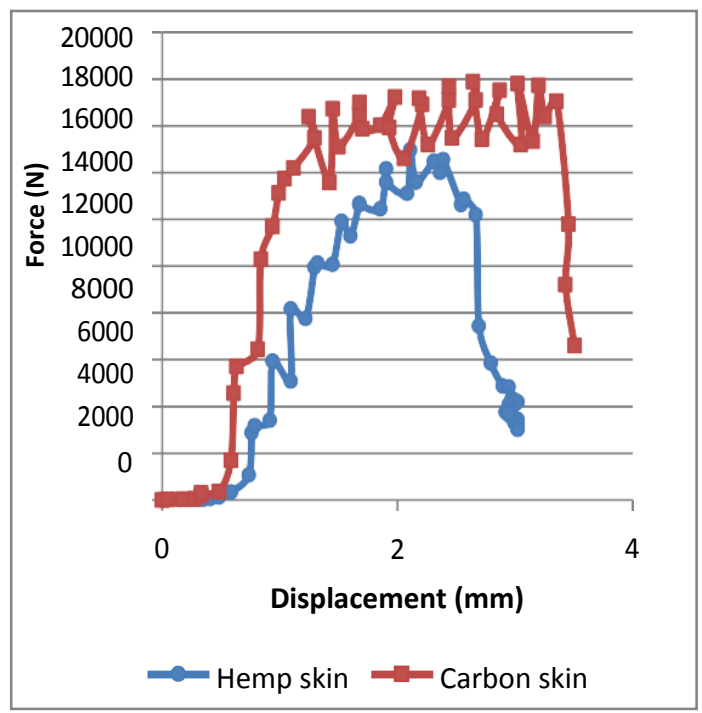

Fig. 8 Force- displacement of foam-core samples of length$2(126 \mathrm{~mm})$

The results in Figure 9 reveals the specific properties of carbon-skin specimens doesn't change significantly with a foam core, the stiffness and force are; $1.66(\mathrm{kN} / \mathrm{mm}) / \mathrm{gm} \&$ $1.6 \mathrm{kN} / \mathrm{gm}$. The samples having the hemp skin are affected by changing the core $(0.91$ $\mathrm{kN} / \mathrm{mm}) / \mathrm{gm} \& 1.12 \mathrm{kN} / \mathrm{gm})$. The hemp supports a relatively high load and it is still comparable to the carbon but the stiffness is degraded. This effect is predicted because of the hemp fabric nature.

\subsection{Carton core}

The same as in wood and foam cores the results of samples of honeycomb paper board (honeycomb carton) core are graphed. Figures 10 and 11 are for the forcedisplacement curves and the properties respectively. Predictively, the curves of both skins (hemp \& carbon) with a soft cellular carton honeycomb core are distinguished by fast collapsing at the least magnitudes of load values. Concerning the specific properties-to-weight ratio, are similar to the foam-core ones, this is for the hemp skin samples. Because the honeycomb is the lightest weight-core in fabricated samples.
The specific properties of the stiffness and the force are; $0.86(\mathrm{kN} / \mathrm{mm}) / \mathrm{gm} \quad \& \quad 1.1$ $\mathrm{KN} / \mathrm{gm}$ for the hemp-skin. Regarding the carbon-skin specimens, the specific stiffness is high; $1.87(\mathrm{kN} / \mathrm{mm}) / \mathrm{gm}$ while the forceto-weight ratio is still comparable to the hemp one $(1.29 \mathrm{KN} / \mathrm{gm})$. So, it seems the hemp thickness used in manufacturing the tested samples is not enough to support so much stiffness with the weaker core material.

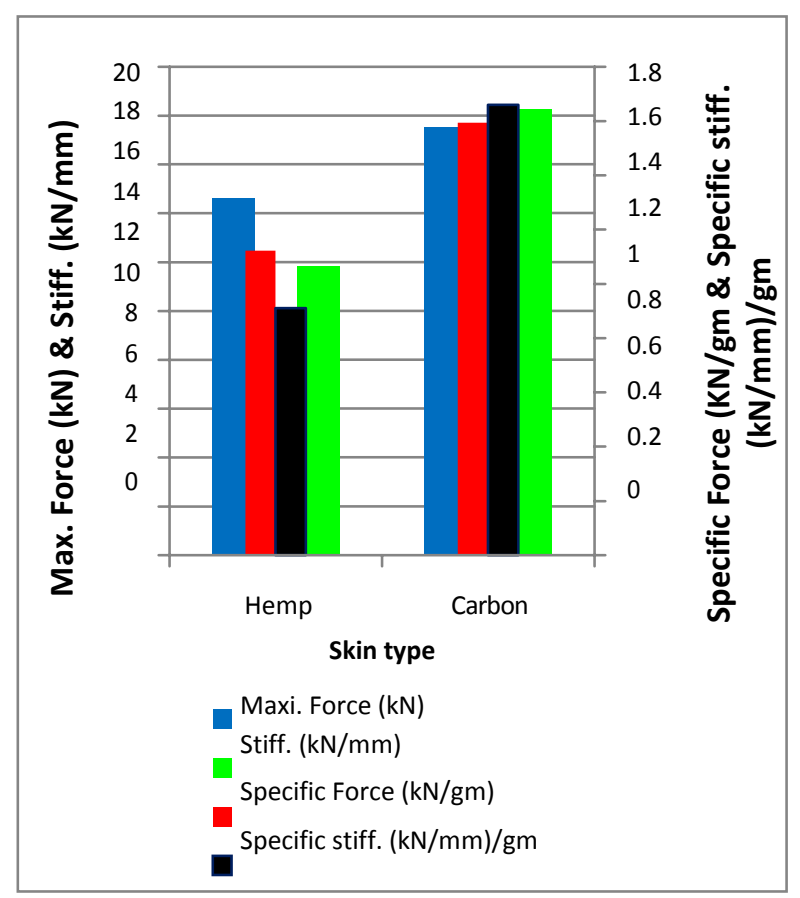

Fig. 9 Properties and specific properties of foam-core samples of length-2 (126mm)

Finally, the hemp-skin sandwich with different core types nearly supports crushing specific compression load as much as a carbon-skin sandwich. Hemp also has comparable specific stiffness with wood core (stiff core), while the carbon-skin sandwich excels on in supporting more specific stiffness with weak cores. So, it is concluded that the hemp thickness used in manufacturing the tested samples not enough to support the weaker core. It is recommended to increase the hemp skin thickness slightly and decreasing the epoxy resin to be capable for sustain more 
compression load without increasing the weight significantly.

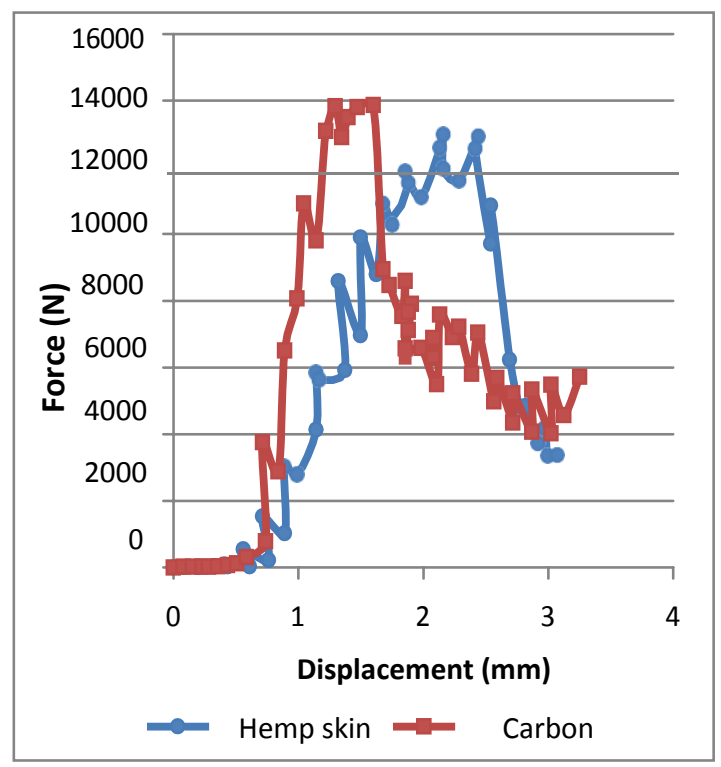

Fig. 10 Force- displacement of honeycomb carton-core samples of length-2 (126 mm)

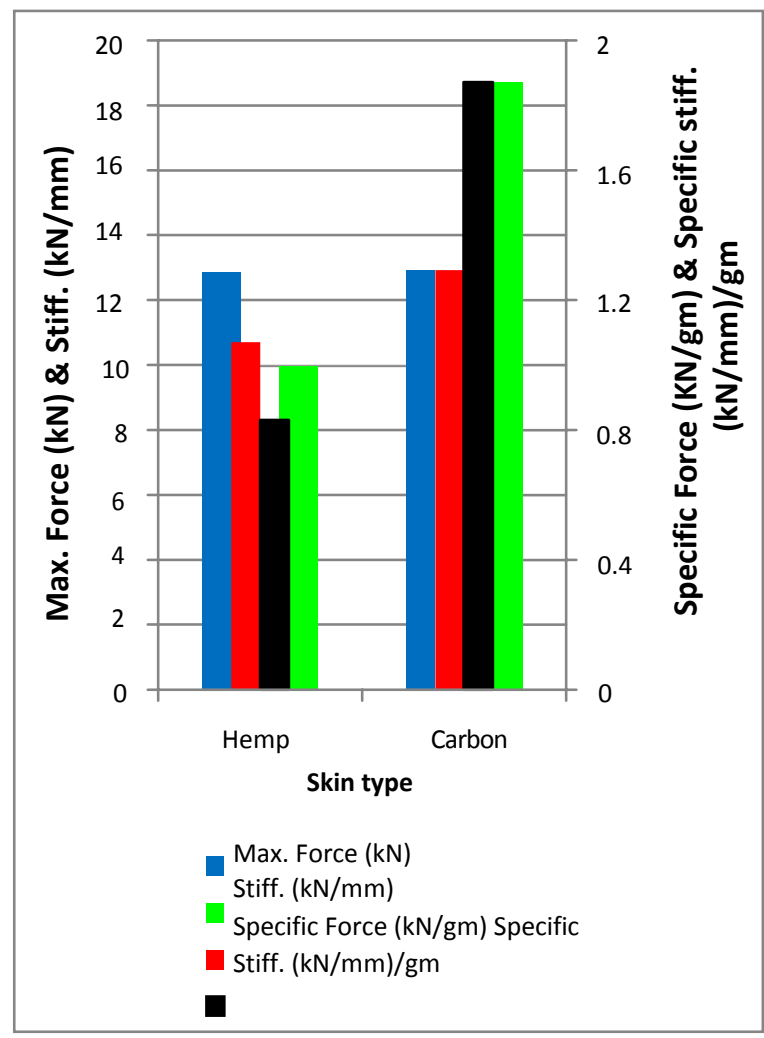

Fig. 11 Properties and specific properties of honeycomb carton-core samples of length-2 (126mm)

\section{FRACTURE MODES}

Figure 12 includes samples of the failure images of the wood-core specimens during the loading and after load releasing. The pictures show the failure of the sandwich of carbon fiber composite is due to the fracture of both skin and wood core at the above surface (contact area to the upper head of the machine). The carbon skin suffers fiber delamination and tearing. On contrary, the failure of the hemp sandwich occurs as a result of the core fracture only. The woodcore fracture between the hemp skins is more severe as a large crack arises in the middle of the core in addition to the rupture at the contact area to the upper head of the compression machine. The hemp skin is kept sound and does not undergo rupture or fiber damage. Regarding the images in Figure 12, they exhibit strong adhesion between the hemp skin and the wood core. Whereas, the shear plane in this sandwich structure is at the underneath layer of wood. In other words, a thin wood layer of the core has been separated from the core and bonded to the hemp skin. The shear plane at the carbon fiber sandwich happened at the resin between the skin and the core. The fracture modes demonstrate better fracture resistance in the composite of the hemp skin than that of the carbon fiber one and prove good wettability of hemp as well. This outcome probably attributes to the less brittleness of the hemp textile fiber than the woven carbon fibers'. Despite the difference in the fracture modes of both skin types, the experimental results demonstrate comparable values of load and stiffness. The failure modes reveal; strong wood core with less damage was more sustainable part than the composite carbon skin. While the hemp skin when strengthened by the bonded wood layer, acts as a new strong skin for load sustainably. These different fracture modes are confirmed with the experimental results. Thus, more advantages are added to the 
sandwich structures when utilizing the hemp material in manufacturing composite skin.
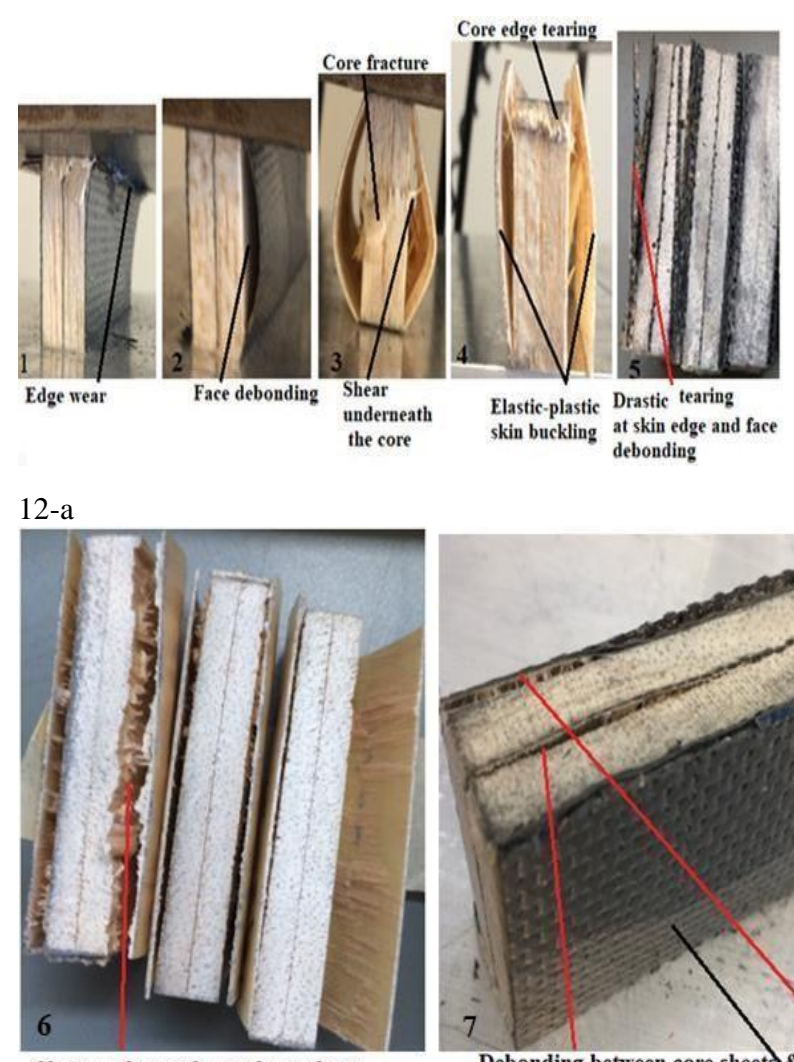

Shear underneath wood core layer

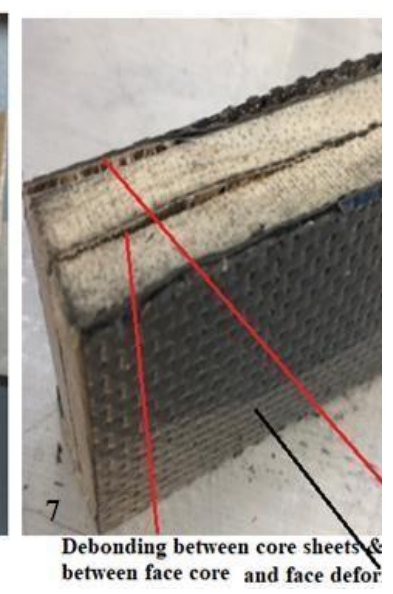

$12-b$

Fig. 12 Failure modes of wood-core composite samples under loading and after load releasing from different views; a) \& b)

The same as wood-core specimens, other failure modes of foam-core samples under loading are shown in Figure 13-a and the images after load releasing are in Figure 13b. It could be concluded from Figure 13, the composite skin with hemp fiber textile after load releasing remains consistent without delamination or fracture but it undergoes wrinkling under loading. The wrinkling occurred at different zones, above, in the middle, and at the bottom. Figure $13(\mathrm{a} \& \mathrm{~b})$ shows good adhesion between the hemp and the foam core. The carbon skin with foam experienced fiber delamination, fracture at edges, and severe tearing as manifested in Figure 13-b. The debonding between carbon skin and the foam core due to the poor adhesion between them was observed in the carbon sandwich.

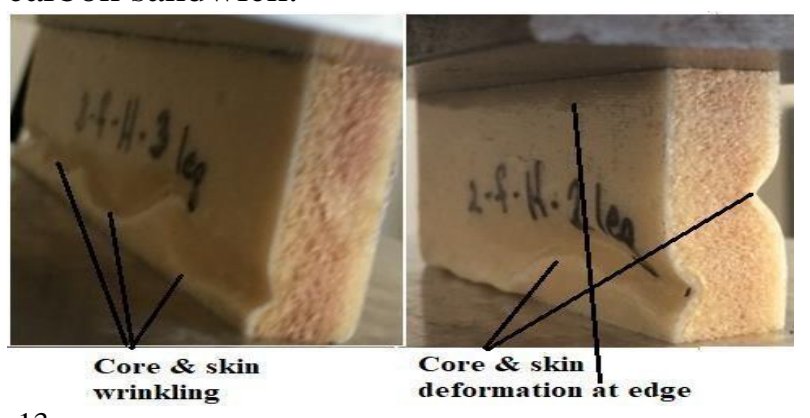
$13-\mathrm{a}$

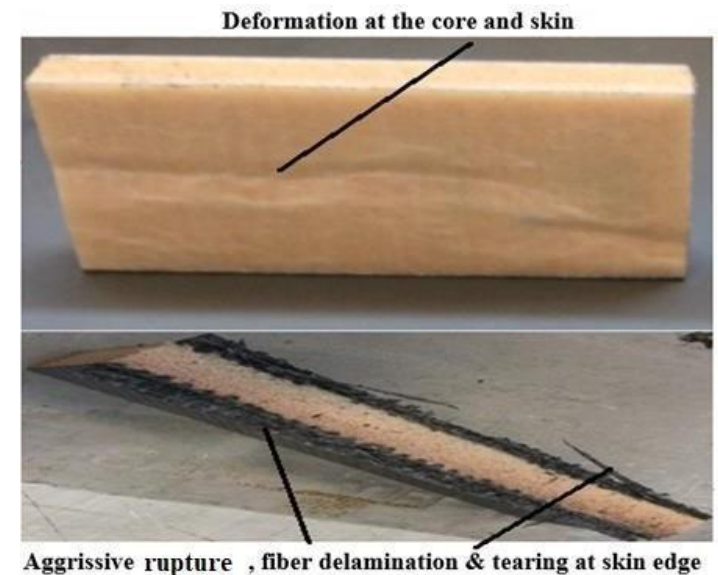

13-b

Fig. 13 Failure modes of foam-core composite samples; a) during loading and $b$ ) after load releasing

As well as, the failure modes of honeycombcore samples are included in Figure 14, before and after loading. The failure modes in the sandwich members of composite hemp skin and honeycomb- core are so far similar to that in the condition of foam core. But more collapse induced with the honeycomb-core. This observation reveals that as the weaker core material inside as the hemp skin composite experiences more wrinkling. The adhesion between the honeycomb core and skin is affected negatively as well. This negative effect is due to the large difference between the opencell core nature and the closed-cell core one. The delamination and fracture are also avoidable in the hemp skin with a honeycomb core. On contrary, different failure modes in the carbon kind happened. These modes are plastic in the carbon skin 
when the debonding between the core and the skin happens late during loading (Figure 14-a). But the deformation is elastic when the early debonding occurred (Figure 14-b). However, plastic deformation is clear from Figure 14-a, which includes a worn skin. And elastic deformations are in Figure 14-b which displays sound carbon skin. The debonding between core and skin refers to the extremely poor adhesion between carbon composite skin and the honeycomb-core. The early separation prevents supporting higher values of force and consequently prohibits rupture or damage in the skin.

Finally, when the core has less stiffness (foam or honeycomb), it behaves elastically under loading and the failure mode is facing wrinkling in hemp skin. Otherwise, buckling failure of the skins happens if the core is sufficiently stiff (wood). The failure modes are similar to ref. [13]. Concerning to the skins, the failure mode is fiber delamination, rupture at the upper edge of carbon skin when the core has high stiffness. Rather than, the failure is face/core debonding in when less core stiffness is utilized. Some failures modes have been observed by [14] in metallic skin sandwiches (general buckling, wrinkling, core crushing, and core/skin debonding) are similar to the composite skin sandwich in the current work [14]. Also, failure mode in the form of tearing at the carbon sheet edges is similar to the same composite sheets when holding fiberglass corrugated laminate core inside [1].

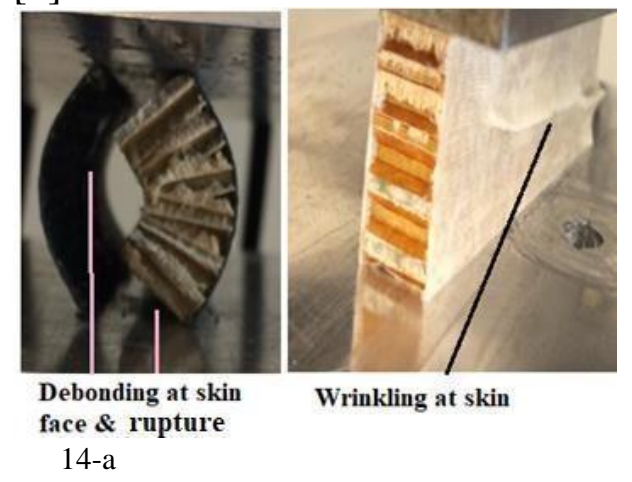

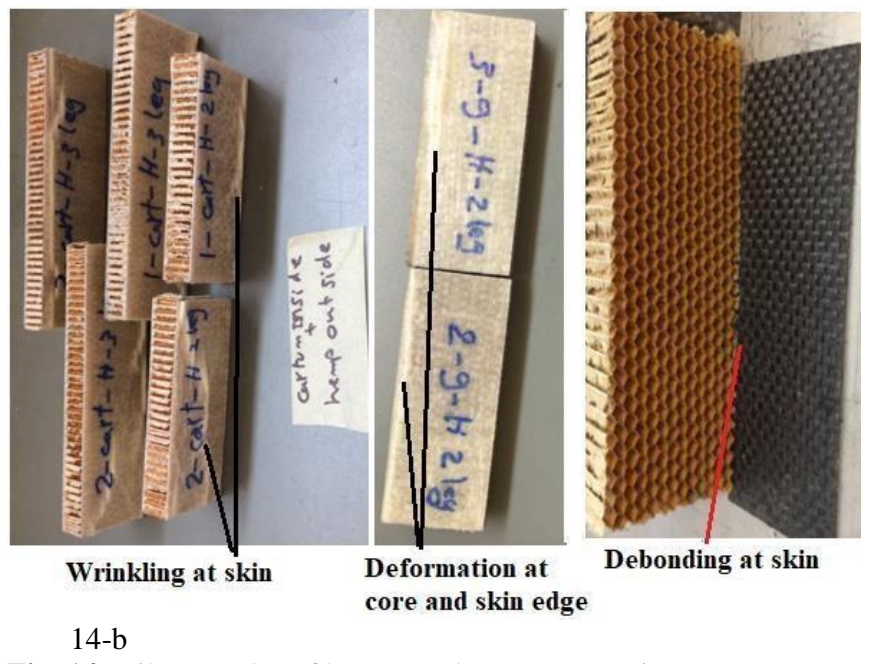

Fig. 14 Failure modes of honeycomb core-composite sandwich; a) during loading and b) after load releasing

\section{CONCLUSIONS}

Rather than the ecological advantages, high strength, good fiber orientation, and fiber distribution, lightweight, low cost, and ease in handling, the strong adhesion between the composite hemp and different kinds of core materials add more advantages when it is utilized in manufacturing the sandwich structure. While Poor adhesion between the composite carbon skin and the same types of the core material is proved experimentally and makes the carbon fiber type disadvantageous in some sandwich applications although its higher stiffness.

The load-supporting by the composite hemp and composite carbon skins in the sandwich structure is comparable in the condition of strong core materials (wood) while in weak core ones (foam and honeycomb) the carbon skin excels the hemp skin in the stiffness properties.

The failure mode is facing wrinkling in hemp skin when the core has less stiffness. Otherwise, buckling failure of the skins occurs if the core is sufficiently stiff. Regarding the skins, the failure mode is facing fiber delamination, fracture rupture at the upper edge of carbon skin when the core 
has high stiffness. Moreover, the failure is deboning between the skin and the core for the less core stiffness.

Hemp skin demonstrates a high resistance to the delamination, fracture, and tearing more than carbon skin while the carbon skin has better resistance to the wrinkling, in the cases of weak cores

Hemp skin proves itself a competitive material in the sustainable interiors for aerospace applications

\section{ACKNOWLEDGMENT}

For their permission for manufacturing and experimental testing in a composite material laboratory. Mechanical Engineering Department members of California Polytechnic State University, USA are gratefully appreciated.

\section{REFERENCES}

[1] Nagwa Elzayady and Eltahry Elghandour, "Compression Capacity of Corrugated Core Hybrid Composite Sandwich Structure", Key Engineering Material, Volume 821, 47-53, September 2019.

[2] Thomas Reußmann and Eric Oberländer, "Novel Honeycomb Sandwich Structures with Fiber Reinforced Face Sheets",58 the Ilmenau Scientific Colloquium Technische Universität Ilmenau, 08 - 12 September 2014, URN: urn:nbn:de:gbv:ilm1-2014iwk:3

[3] Nagwa Elzayady and Eltahry Elghandour, "Comparison between honeycomb and composite corrugated cores in sandwich panels under compression loading", Int. J. Sustainable Materials and Structural Systems, Vol. X, No. Y, xxxx; DOI: 10.1504/IJSMSS.2020.10032340 [4] Nagwa Elzayady and Eltahry Elghandour, "Compression Behavior of Composite Sandwich Panels with Corrugated Core", Int. J. Sustainable Materials and Structural Systems, Vol.X,No.Y,xxxx;

DOI: 10.1504/IJSMSS.2020.10032262

[5] Małgorzata JANUS-MICHALSKA and Dorota JASIŃSKA, "Comparative Study Of Bending Stiffness Of Sandwich Plates With Cellular Cores", RUTMech, t. XXXIV, z. 89
(2/17), kwiecień-czerwiec, s. 203-210, 2017;

DOI: $10.7862 / \mathrm{rm} .2017 .17$

[6] Pydah, A.; Batra, R.C., "Blast Loading of Bumper Shielded Hybrid Two-Core Miuraori/Honeycomb Core Sandwich Plates", Thin. Wall. Struct. 129, 45-57, 2018.

[7] Giglio, M.; Gilioli, A.; Manes, A. "Numerical Investigation of a Three-Point Bending Test on Sandwich Panels with Aluminum Skins and Nomex ${ }^{\mathrm{TM}}$ Honeycomb Core", Comput. Mater. Sci. 56, 69-78, 2012.

[8] Foo, C.C.; Chai, G.B.; Seah, L.K. "A Model to Predict Low-Velocity Impact Response and Damage in Sandwich Composites", Compos. Sci. Technol. 68, 1348-1356, 2008.

[9] Joseph D. Bronzino, "Biomedical Engineering Fundamentals", CRC Press, third edition, Section V, CHAPTER 41, by Roderic Lakes, 2006.

[10] Hartoni, J. Fajrin, B. Anshari, and A.D. Catur, "Effect Of Core And Skin Thicknesses Of Bamboo Sandwich Composite On Bending Strength", International Journal of Mechanical Engineering and Technology (IJMET) Volume 8, Issue 12, pp. 551-560, December 2017.

[11] Aiea A. Elhabak, Mostafa Shazly, Tarek A. Osman1 and Aly A. Khattab1, "Mechanical Behavior Of Aluminum Hybrid Laminates", Journal of Engineering and Applied Sciences, VOL. 14, NO. 20, 3455-3462, OCTOBER 2019 [12] Zaini, E.S.; Azaman, M.D.; Jamali, M.S.; Ismail, K.A., "Synthesis and Characterization of Natural Fiber Reinforced Polymer Composites as Core for Honeycomb Core Structure": A review. J. Sandw. Struct. Mater. 22, 525-550, 2020.

[13] Sukmaji Indro Cahyono, Angit Widodo, Miftahul Anwar, Kuncoro Diharjo, Teguh Triyono, A Hapid , S Kaleg2, "Light-Weight Sandwich Panel Honeycomb Core With Hybrid Carbon-Glass Fiber Composite Skin For Electric Vehicle Application", AIP Conference Proceedings 1717, 040025 (2016)

[14] M.I. Misnon, M.M. Islam, J.A. Epaarachchi , K.T. Lau, "Analyses Of Woven Hemp Fabric Characteristics For Composite Reinforcement", Materials And Design”, 66, 8292, (2015)

[15] Serge Abrate "Advances in Composite Sandwich Structures and their Behaviour under Impact", Conference: ICILSM (2016) 
[16] Banoth Ganesh, and B VIjay Kumar, D. Muppala, "Design And Structural Analysis Of Aircraft Floor Panel", International Journal of Advanced Engineering and Global Technology I Vol-03, Issue-12, 1451- 1460, December (2015). [17] G Ramakrishnan, B. Vijaya Ramnath, C.Vignesh, L.Vignesh, T.Perunddevan and $M$ VidhyaRajan, "Sandwich and Natural fiber composites - A review", IOP Conf. Series: Materials Science and Engineering 390, 012067, (2018); doi:10.1088/1757-899X/390/1/012067

[18] João P. Manaia 1,*, Ana T. Manaia 1 and Lúcia Rodriges, "Industrial Hemp Fibers: An Overview", Fibers 7, 106, 1-16, (2019); doi:10.3390/fib7120106

[19] Niyati Shah, Joseph Fehrenbach and Chad A. Ulven, "Hybridization of Hemp Fiber and Recycled-Carbon Fiber in Polypropylene Composites", Sustainability 11, 3163, 1-12, (2019); doi:10.3390/su11113163

[20] Salvatore Musio, Jörg Müssig and Stefano Amaducci, "Optimizing Hemp Fiber Production for High Performance Composite Applications", Front. Plant Sci. 9:1702, (2018); doi: 10.3389/fpls.2018.01702.

[21] Taneli Väisänen Paolo Batello Reijo Lappalainen LauraTomppo , "Modification of hemp fibers (Cannabis Sativa L.) for composite applications", Industrial Crops and Products Vol. 111, 422-429, January (2018).

[22] Sandip Haldar, Hugh A. Bruck

"Mechanics of composite sandwich structures with bioinspired core", Composites Science and Technology $95 \quad$ (2014) 67-74; DOI: 10.1016/j.compscitech.2014.02.011

[23] Zongwen $\mathrm{Li} *$ and Jianxun Ma, "Experimental Study on Mechanical Properties of the Sandwich Composite Structure Reinforced by Basalt Fiber and Nomex Honeycomb", Materials 13, 1870, 1-17, 16 April (2020).

[24]https://www.ecologicaltextiles.nl/contents/e n-uk/d7_Hemp.html, January 2020

[25] E.E Gdoutos1 and I.M. Daniel, "Failure Mechanisms Of Composite Sandwich Structures", September (2009), https://www.researchgate.net/publication/25267 3934_Failure_Mechanisms_of_Composite_Sand wich_structures.

[26] Paul M. Jenkinson, "Edgewise Compressive Properties Of Titanium And Nickel-Base
Sandwich Constructions At Elevated Temperatures", U. S. Forest Service Research Paper FPL, This Report Is One Of A Series Issued In Cooperation With The Mil-Hdbk-23 Working Group On Composite Construction For Aerospace Vehicles Of The Departments Of The Air Force, Navy, And Commerce, 68 November (1966).

[27] M.S. Sham Prasad, C.S. Venkatesha, T. Jayaraju, "Experimental Methods of Determining Fracture Toughness of Fiber Reinforced Polymer Composites under Various Loading Conditions", Journal of Minerals \& Materials Characterization \& Engineering, Vol. 10, No.13, pp.1263-1275, (2011)

[28] Remon A. Mankarious, Mostafa A. Radwn, Mostafa Shazly, and Hany A. Elszab, "Bulletproof Vests/Shields Prepared from Composite Material based on Strong Polyamide Fibers and Epoxy Resin", Journal of Engineering and applied science 12 (10): 2697- 2701, (2017). [29] Dahshan, B., El-Habbak, A.-H. M., Adly, M. A., Shazly, M., "Experimental And Numerical Study On The Tensile, Three-pointBending, And Interlaminar Fracture Toughness of GLARE", Journal of Mechanical Science and Technology 34 (8) 3273-3281, (2020).

[30] A.M. Elhabak, A.Nabil, M.Adly, and Nagwa Elzayady, "Behaviour Of Hybrid Composite Structure Under Low Impact Velocity", Journal of Advamced sceinces, 15: 2772-2780, (2020).

[31] G. Ramakrishnan et al, "Sandwich and Natural fiber composites" A review, IOP Conf. Series: Materials Science and Engineering 390 (2018) 012067, (2018). 